\title{
Monitoring Grassland Desertification in Zoige County Using Landsat and UAV Image
}

\author{
Mingguang $\mathrm{Tu}^{1}$, Hong $\mathrm{Lu}^{2 *}$, Min Shang ${ }^{3}$ \\ ${ }^{1}$ Jiangxi Key Laboratory of Industrial Ecological Simulation and Environmental Health in the Yangtze River Basin, \\ Jiujiang University, Jiujiang 332005, China \\ ${ }^{2}$ Research Institute of Social Development, Southwestern University of Finance and Economics, Chengdu 610000, China \\ ${ }^{3}$ Sichuan Solid Waste and Chemicals Management Center, Chengdu 610000, China
}

Received: 31 January 2021

Accepted: 27 April 2021

\begin{abstract}
The increasing rate of sandy desertification lands in Zoige County has been regarded as an imminent threat recently. There is an urgent need to monitor the status, trend of desertification. This study used a land cover classification process of integrating Support Vector Machine classifier (SVM) with threshold method to extract the sandy lands based on Landsat data collected from 1990 to 2017. Furthermore, we quantitatively analyzed the evolution trend of the grassland desertification and verified the effect of desertification control using the unmanned aerial vehicle (UAV) image acquired in 2019. Three conclusions are drawn from the study. First, the sandy land is mainly distributed along the directions of prevailing wind at the edges of mountains in the southwest. Second, the area of sandy lands increased from $29.75 \mathrm{~km}^{2}$ in 1990 to $46.87 \mathrm{~km}^{2}$ in 2005 and then decreased to $22.58 \mathrm{~km}^{2}$ in 2013. While during 2014-2017, the area increased to $33.61 \mathrm{~km}^{2}$. Third, the increasing of sandy lands is closely related to the terrain and water resources distribution. Ecological restoration policies, especially the ecological recovery projects implemented are the main driving factor of desertification reversion. The results of this study can provide effective data and decision support for combating desertification.
\end{abstract}

Keywords: desertification, supervised classification, Zoige County, Landsat and UVA image, information extraction

\section{Introduction}

Desertification, one of the most serious global issues, is the persistent degradation of ecosystems principally in semiarid and arid areas due to both environmental changes and human activities [1,2]. Across the Earth's surface, approximately $25 \%$ of dryland is under

*e-mail: luhong0317@163.com threat from desertification and approximately $32 \%$ of the world's population, $67 \%$ of countries are either directly or indirectly affected by desertification [3-5]. There have been economic losses of approximately US $\$ 42.3$ billion due to worldwide desertification [6]. In China, grassland is the largest land resource and accounts for $41.7 \%$ of the country's total land surface. However, numerous scientific and government reports note that roughly $90 \%$ of Chinese grasslands have been degraded to varying degrees [7]. Zoige County 
which located in the north of Aba prefecture in Sichuan Province is the green ecological area defending the upper reaches of Yellow River and Yangtze River. The ecosystem including forests, grasslands and wetlands in Zoige County plays an important role in regulating climate, conserving water resources, preventing flood and drought, purifying water quality, etc. In recent years, however, the area of desertified grassland in Zoige County has undergone constant expansion due to topography, geological structure, regional climate factors and human activities, which seriously threatens the sustainable development of local society and economy and the ecological security of the middle and lower reaches of the Yellow River. As such, there is an urgent need to take steps to monitor and to prevent the increasing desertification lands. Presently, field surveys of vegetation, rocky outcrop cover, slope and soil distribution is still the primary way to quantitatively estimate the extent of desertification lands in Zoige County. The methods are time consuming, expensive, and limited by large spatial scales and rugged terrain [8].

Remote sensing, with its capability to reliably and to rapidly collect data over wide areas, offers quick updates and an abundance of information [9]. This method has been popularly applied to monitor desertification and its dynamic in arid and semiarid areas since the 1970s [10-13]. Landsat Multispectral Scanner (MSS) and Landsat TM are the commonly used optical satellite images, featuring 30-meter resolutions which are useful for extracting land cover and change conditions at regional scales [14]. Typically, the methods of mapping and monitoring grassland desertification based on remote sensing can be classified into three main categories. The first group is spectral and texture index-based approaches [15-18], including the fractional vegetation cover (FVC), the normalized difference vegetation index (NDVI), modified soil adjusted vegetation index (MSAVI), Albedo, land surface temperature (LST), the topsoil grain size index (TGSI), Albedo-NDVI, Albedo-MSAVI, and Albedo-TGSI [19-26]. Of these indicators, NDVI is one of the most used for monitoring grassland desertification [27-30]. However, because of mixed land cover and topography, none of the existing vegetation indices could be directly used as an indicator to monitor the desertification [31]. The second group is spectral mixture analysis (SMA) methods. The approaches assume that reflectance for one pixel is a linear mixture of several endmembers and that each endmember is a unique land cover type with a specific spectral signature [32, 33]. The aim of SMA is to decompose mixed spectra and calculate proportions of each land cover type in a single pixel $[34,35]$. It should be noted that the assumption is not universally valid and the SMA method is often limited by the variability of endmembers, particularly for highly heterogeneous landscapes [36]. The third group is image classification. Researchers have used the original reflectance data and/or these indices as input for statistically modeling desertification status using supervised classification, decision tree and SVM [37, 38].

Considering all the above, the objective of this study is to monitor the dynamics changes of desertification in Zoige County as a means of supporting of regional sustainable development. For this purpose, we first applied SVM to automatically obtain the land cover classification in Zoige country County from 1990 to 2017 based on Landsat image data with the help of eCognition10.1. And then, the accuracy of land cover classification was evaluated by confusion matrix. Finally, we analyzed the trends of desertification by comparing the areas of sandy land in different years with UAV images being utilized to verify the effect of desertification controlling in recent years. The result of this study could aid in understanding the dynamics of the ecological environment in Zoige County and provide the basic data for further analysis on the driving force of desertification.

\section{Materials and Methods}

\section{Study Area}

Zoige County is located in the northwestern part of Sichuan Province, China, and has an area of $10,620 \mathrm{~km}^{2}$.It is determined by the limits of $32^{\circ} 56^{\prime} \mathrm{N}$ and $34^{\circ} 19^{\prime} \mathrm{N}$ in latitude and of $102^{\circ} 08^{\prime} \mathrm{E}$ and $103^{\circ} 39^{\prime} \mathrm{E}$ in longitude, as shown in Fig. 1. Zoige County falls in humid monsoon climate zone of cold temperate plateau with an average annual temperature of $1.1^{\circ} \mathrm{C}$ and average annual precipitation of $656.8 \mathrm{~mm}$. More than $70 \%$ of the rainfall is received during the two months from late May to mid-July. Zoige County has a considerably complex topography, including mountains, plateaus, hills, and valleys. The mountains and valleys in the territory are deep and the terrain is steep, with an altitude of 2,400 meters to 4,200 meters. There is no absolute frost-free period in the area. Every year, the land starts to freeze in late September and thaws completely in mid-May. Zoige County is predominantly a pastoral area and the herding, agriculture are the primary economic activities. The population in the area was 82,000 in 2019.

\section{Data and Preprocessing}

The remote sensing data used in this study were downloaded from the open access archive of the Geospatial Data Cloud (http://www.gscloud.cn/). Due to the limitations of cloud and time resolution, $84 \mathrm{high}$ quality Landsat images (TM, ETM+ and OLI) with 30-m spatial resolution obtained from 1989 to 2017 were available for this study. The details are shown in Table 1. The data product is level $1 \mathrm{R}$ with radiometric calibration atmospheric, topographical, and geometric correction. The spectral bands that have been used in 


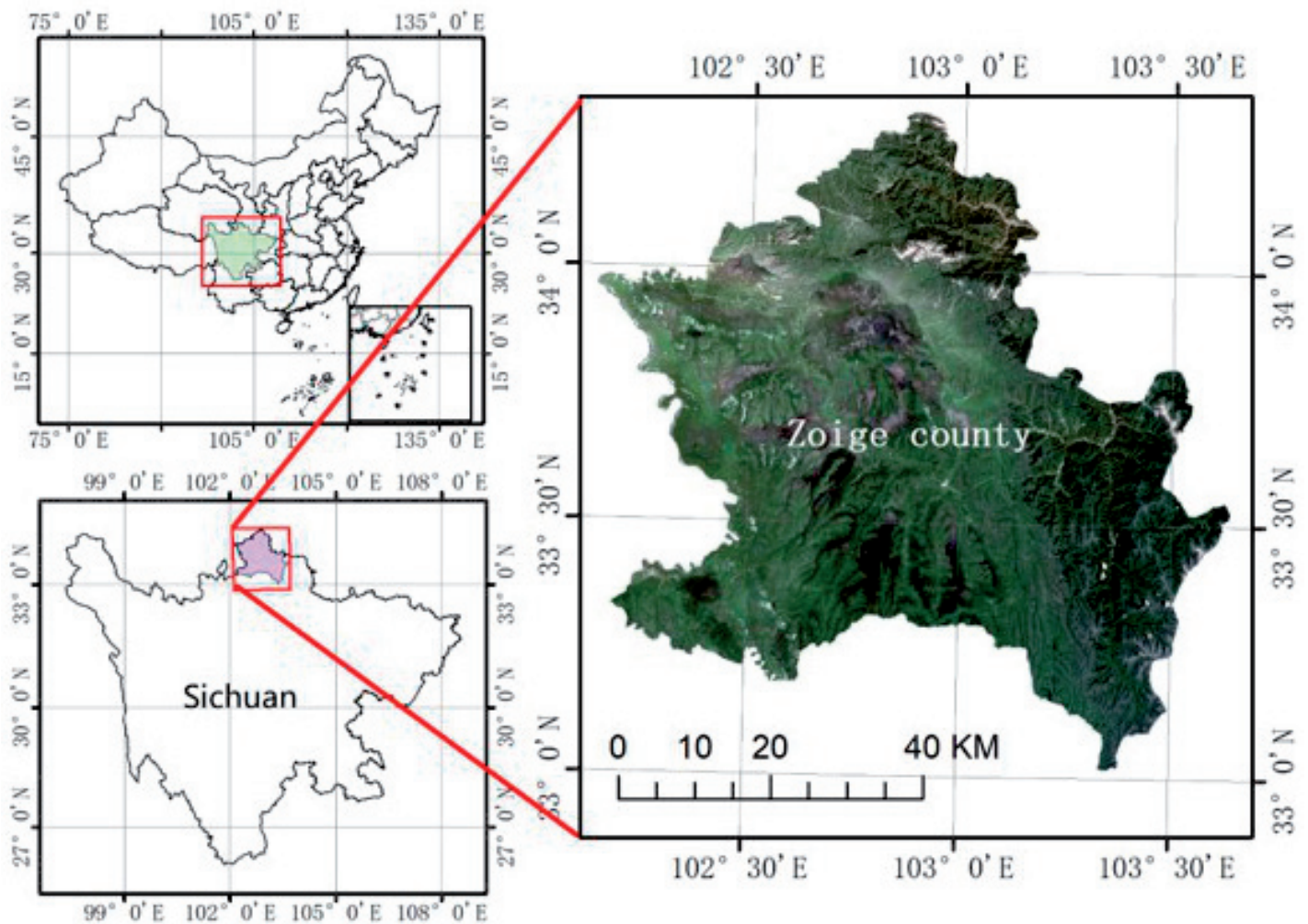

Fig. 1. Location of the study area.

the study are the Green, Blue, Red and Near Infrared. Satellite image preprocessing was carried out via ENVI 5.1. A layer-stacking tool was used to convert the four bands into a layer file and mosaic them into a single file for each period. Due to the large geographic coverage, it was difficult to acquire cloud-free images that cover the whole study area within a given year. Therefore, we used some images from subsequent or previous years to generate a cloud-free mosaic. DEM data were downloaded from ASTER satellite images (http://www. jspacesystems.or.jp/en_/). All the images were projected in WGS 1984 UTM zone $48 \mathrm{~N}$ and subset/clipped to the study area.

The UAV image data used for this study were obtained in the field from July 9 to 10,2019 , as presented in Fig. 2. The desertification problem highlighted as three points in the figure is very serious. We obtained 80 UAV images from the first point, 135 images from the second point and 68 images from third point. By using Photoscan software, we aligned the UAV images, established a dense point cloud, generated a grid, as well as the texture, and built a tile model and DEM. Finally, ortho correction images at the three monitoring points were obtained.

\section{Methods}

\section{The Workflow of Classification}

This study used eCoginition10.1 software to classify the Landsat images and extracted sandy lands based on a combinatorial algorithm of SVM and threshold method. The workflow is as follows (Fig. 3).

First, we segmented the entire image at a pixel level using chessboard segmentation algorithm and generated image object layer of Level 1. The parameter of object size was set to one. We extracted vegetation at Level 1 based on the NDVI index. The threshold value of NDVI was adjusted according to Landsat images. Second, we used multiresolution segmentation algorithm to segment

Table 1. List of remote sensing image data.

\begin{tabular}{|c|c|c|c|c|}
\hline Satellite & Sensor & Imaging Date & Number of images & Number of bands \\
\hline Landsat 4 & TM & 1989 & 2 & 7 \\
\hline Landsat 5 & TM & $1990-2011$ & 40 & 7 \\
\hline Landsat 7 & ETM+ & $1999-2011$ & 21 & 8 \\
\hline Landsat 8 & OLI & $2013-2018$ & 21 & 9 \\
\hline
\end{tabular}




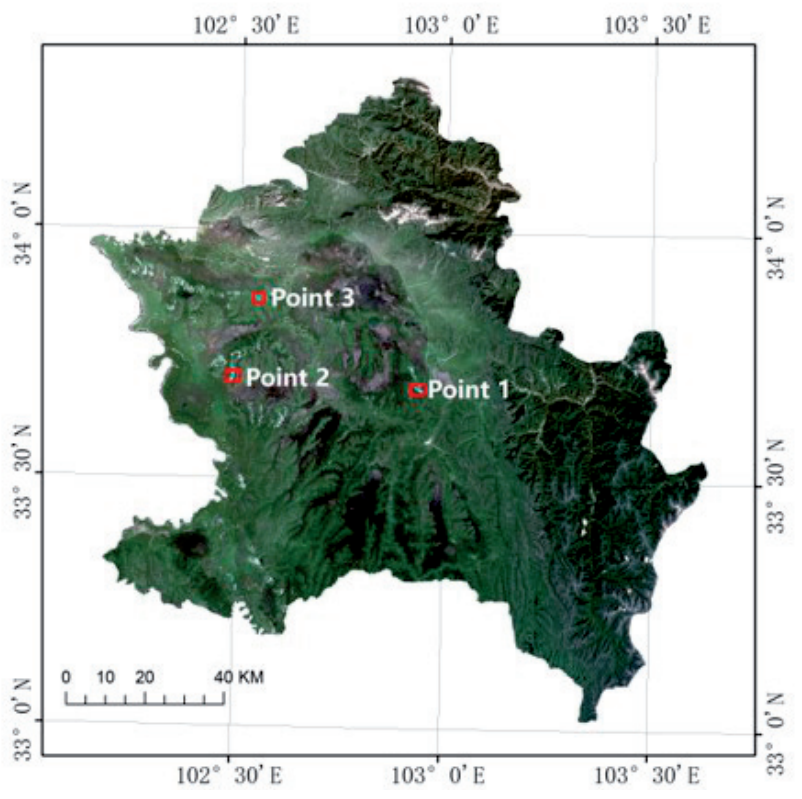

Fig. 2. UAV aerial photography points.

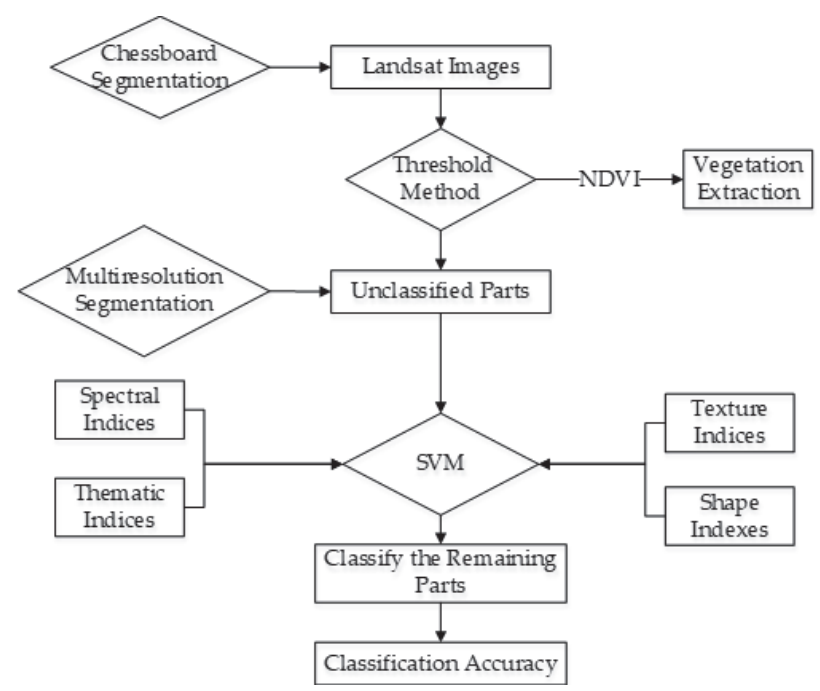

Fig. 3. The workflow of classification.

the unclassified parts and generated image object layer of Level 2 at a larger object scale. The parameters of shape and compactness were adjusted to acquire fairly integrated image objects for different types of land cover. We used the SVM and some additional features to classify the remaining parts. Third, 1,000 random sample points were selected to evaluate the classification accuracy based on a confusion matrix.

\section{SVM and Features Used for Classification}

SVM is a supervised learning model derived from statistical learning theory. The algorithm distinguishes between classes with the decision that maximizes the margin between them. Given a set of training examples, $\left\{\left(x_{i}, y_{i}\right)\right\}_{i=1}^{n}$, and Kernel function $K$, each $y_{i}=\{-1,+1\}$ is marked as belonging to one of two categories. An SVM object function is used to solve the optimization problem as:

$$
\begin{gathered}
\max \left\{\sum_{i=1}^{n} \alpha_{i}+\sum_{i, j=1}^{n} \alpha_{i} \alpha_{j} y_{i} y_{j} K\left(x_{i}, x_{j}\right)\right\} \\
\text { s.t. } \quad 0 \leq \alpha_{i} \leq C, \sum_{i=1}^{n} \alpha_{i} y_{i}=0
\end{gathered}
$$

...where $\alpha s$ are the Lagrange coefficients and $C$ is a constant that is used to penalize the training errors of the samples. SVM is affected by the selection of regularization parameters $\alpha s$ and the form of the kernel function $K\left(x_{i}, x_{i}\right)$ [39]. In this study, we selected the Gaussian Radial Basis Function (RBF) as the Kernel function and used the Library for Support Vector Machines (LIBSVM) to obtain the value of two parameters for RBF. One parameter is the optimum Gaussian radial basis function $\gamma$, which controls the kernel width. Another is the regularization parameter $C$ mentioned above.

The features used for classification were listed in Table 2.

\section{Results \\ Land Cover Classification and Accuracy Assessment}

We first classified the Landsat images from 2017 due to this set offering the highest level of image quality. The mapped land cover classes of Zoige County in 2017 can be seen in Fig. 4 and include sandy land, farmland,

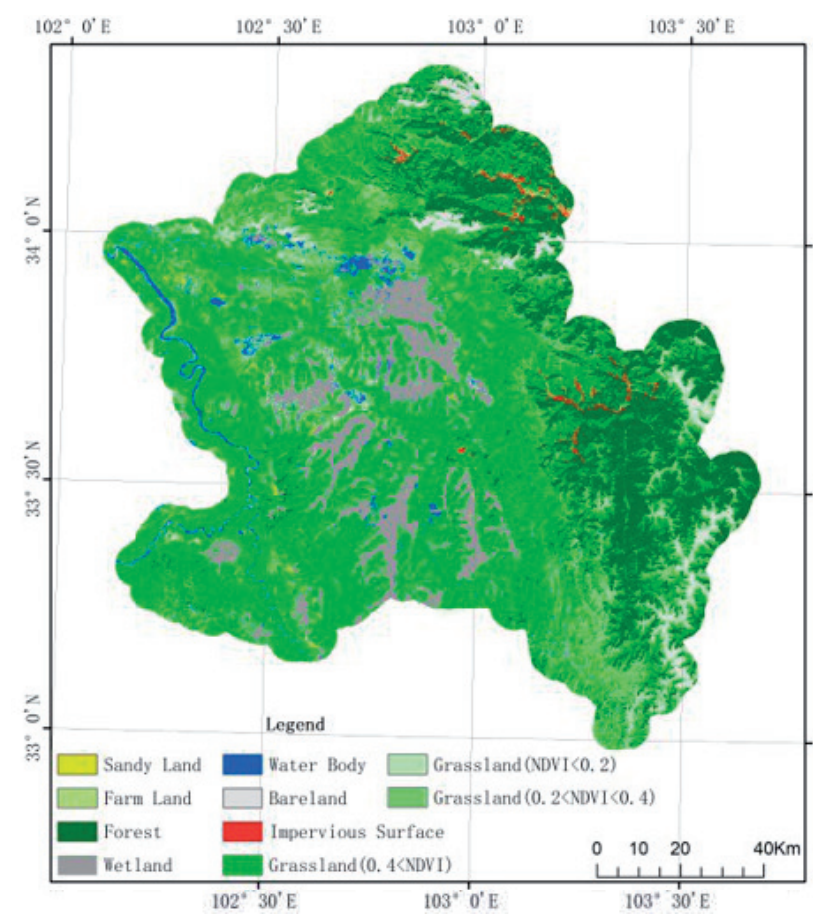

Fig. 4. Classification map of Zoige County in 2017. 
Table 2. Features used for land cover classification.

\begin{tabular}{|c|c|c|c|c|c|}
\hline Textural features & Formulae & Shape indices & Formulae & Thematic indices & Formulae \\
\hline Homogeneity & $\sum_{i=0}^{N-1} \sum_{j=0}^{N-1} \frac{g(i, j)}{1+|i-j|}$ & LWI & $\frac{L}{W}$ & NDVI & $\frac{N I R-R}{N I R+R}$ \\
\hline Contrast & $\sum_{i=0}^{N-1} \sum_{j=0}^{N-1} g(i, j)|i-j|$ & Shape & $\frac{P}{4 \sqrt{A}}$ & NDWI & $\frac{G-N I R}{G+N I R}$ \\
\hline Energy & $\sum_{i=0}^{N-1} \sum_{j=0}^{N-1} g(i, j)^{2}$ & Edge & $\frac{P}{2 *(L+W)}$ & NDBI & $\frac{B-N I R}{B+N I R}$ \\
\hline Entropy & $\sum_{i=0}^{N-1} \sum_{j=0}^{N-1} g(i, j) \log g(i, j)$ & & & SBI & $\sqrt{R^{2}+N I R}$ \\
\hline
\end{tabular}

Note: For Table 2, $(i, j)$ are the coordinates in the co-occurrence matrix space; $g(i, j)$ is the co-occurrence matrix value at that coordinate; $N$ is the dimension of the co-occurrence matrix; $L, W, P, A$ are the length, width, perimeter, area of an image object, respectively; NIR, $R, G, B$ represent the value of near-infrared, red, green, and blue bands, respectively.

Table 3. Accuracy assessment of land cover classification in 2017.

\begin{tabular}{|c|c|c|c|c|c|c|c|c|c|}
\hline Class & $\begin{array}{c}\text { Sandy } \\
\text { Land }\end{array}$ & $\begin{array}{c}\text { Farm } \\
\text { Land }\end{array}$ & Forest & Wetland & $\begin{array}{c}\text { Water } \\
\text { Body }\end{array}$ & Grassland & Bareland & $\begin{array}{c}\text { Impervious } \\
\text { Surface }\end{array}$ & $\begin{array}{c}\text { User's } \\
\text { Accuracy }\end{array}$ \\
\hline Sandy Land & 25 & 0 & 0 & 0 & 4 & 1 & 3 & 0 & $75.76 \%$ \\
\hline $\begin{array}{c}\text { Farm } \\
\text { land }\end{array}$ & 0 & 25 & 2 & 3 & 0 & 5 & 0 & 0 & $71.43 \%$ \\
\hline Forest & 0 & 0 & 123 & 3 & 2 & 10 & 0 & 0 & $89.13 \%$ \\
\hline Wetland & 0 & 0 & 0 & 117 & 14 & 13 & 0 & 3 & $79.59 \%$ \\
\hline $\begin{array}{c}\text { Water } \\
\text { Body }\end{array}$ & 0 & 0 & 0 & 7 & 62 & 6 & 2 & 0 & $80.52 \%$ \\
\hline Grassland & 3 & 15 & 7 & 19 & 13 & 428 & 5 & 2 & $86.99 \%$ \\
\hline Bareland & 3 & 0 & 0 & 0 & 2 & 5 & 45 & 2 & $78.95 \%$ \\
\hline $\begin{array}{c}\text { Impervious } \\
\text { Surface }\end{array}$ & 1 & 0 & 0 & 0 & 0 & 3 & 2 & 15 & $71.43 \%$ \\
\hline Producer's accuracy & $78.13 \%$ & $62.5 \%$ & $93.18 \%$ & $78.52 \%$ & $63.92 \%$ & $90.87 \%$ & $78.95 \%$ & $68.18 \%$ & 7 \\
\hline
\end{tabular}

Overall accuracy: $84 \%$; kappa coefficient: $77.6 \%$

forest, wetland, water body, bareland, and grassland with different coverage. The accuracy assessment of the land cover classification based on 1000 random sample points is shown in Table 3. The overall accuracy is $84 \%$, and the kappa coefficient is $77.6 \%$. Some sandy lands were misclassified as bareland due to high similarity in the features of the image object. The accuracy assessment results indicate that we have acquired a relatively objective land cover classification. We updated the land cover classification in other years based on the 2017 data and extracted the corresponding sandy lands.

\section{Spatial-Temporal Distribution and Trend of Desertification in Zoige County}

From the perspective of the desertification's spatial distribution, sandy lands mainly have concentrated in four contiguously zonal areas since 1990, as shown in Fig. 5. The distribution pattern of grassland desertification in Zoige County has remained stable overall. The sandy land in No. 1 area is in MaiXi Township, extending from northwest to southeast, and largely distributed along the peaks of Zaregama, Adangqiao, Zarexiejian. No. 2 is in XiaMan Township, along Maidoganglan, Quruzhaka peaks. 


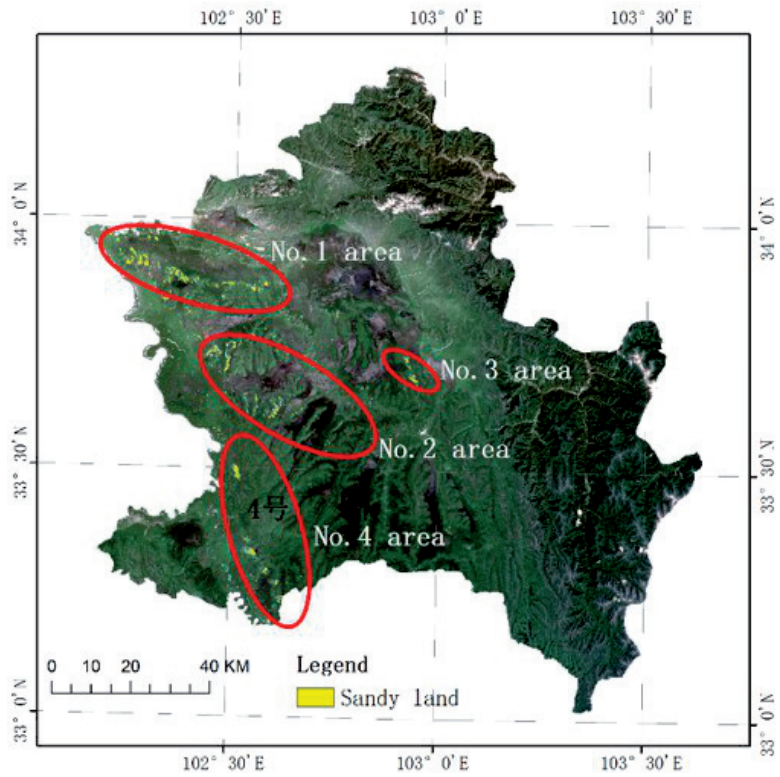

Fig. 5. Spatial distribution of desertification in Zoige County.

No. 3 desertification area is in AXi Township, mainly distributed in the vicinity of Xiemana, Xiemajan and Qumupeng peaks. No. 4 area is in TangKe Town, extending from Xiedong Village in the northwest to the vicinity of Zeejian Mountain in the southeast.

Fig. 6 shows the area changes of sandy land in Zoige County from 1990 to 2017. In recent 30 years, the changing trend of sandy land area within the grassland can be characterized by an "N" type variation structure.

During a fifteen-year period from 1990 to 2005, the sandy land area increased from $29.75 \mathrm{~km}^{2}$ to $46.87 \mathrm{~km}^{2}$, with an average annual growth rate of $2.44 \%$ (about $1.14 \mathrm{~km}^{2}$ ). In the first decade, the sandy land area increased steadily, while in the last five years of this particular period, the sandy land area increased rapidly. From 1990 to 1994, the increase of sandy land area in Zoige County was mainly concentrated in the XiaMan Township of the No. 2 area in the middle of the county (Fig. 7a). During 1994-1999 and 1999-2005, the increase of grassland desertification area was mainly concentrated in No. 1 MaiXi Township, while the desertification area in No. 2 XiaMan Township decreased to a certain extent (Fig. 7b, c). From the overall time sequence (1990-2005), the increase of grassland desertification area mainly concentrated in No. 1 MaiXi Township (Fig. 7d). In addition, the sandy land area also increased to a certain extent in $\mathrm{AXi}$ Township of area No. 3 and TangKe Township of area No. 4.

By comparing the changes of grassland desertification in Zoige County from 1990 to 2005, it can be seen that the increase in the area of grassland desertification is mainly manifested in two forms: the first is the outward expansion at the edge of the original desertified land (Fig. 8a); the second is the addition of spotty sandy patches (Fig. 8b). The increase of grassland desertification in Zoige County is mainly in the periphery of the original desertification patches, but there are a few newly increased desertification patches.

During the eight years from 2005 to 2013, the grassland sandy land area in Zoige County decreased rapidly to $22.58 \mathrm{~km}^{2}$, with an average annual decrease of $3.04 \mathrm{~km}^{2}$. The spatial change was shown in Fig. 9a). The trend led to a significant reduction in Zoige County's sandy land area (Fig. 9b).

From 2013 to 2017, the sandy land area showed an increasing trend, with a total increase of $11.03 \mathrm{~km}^{2}$ and an annual increase of $2.76 \mathrm{~km}^{2}$. The spatial change is shown in Fig. 10. During this period, there was a trend of desertification in the areas land that had been reclaimed by reforestation. The sandy land area increased obviously, but there was still a slight decrease in the sandy land area.

\section{Discussion}

Though the space-time evolution of grassland desertification in Zoige County has been affected by many factors, the local natural environment conditions,

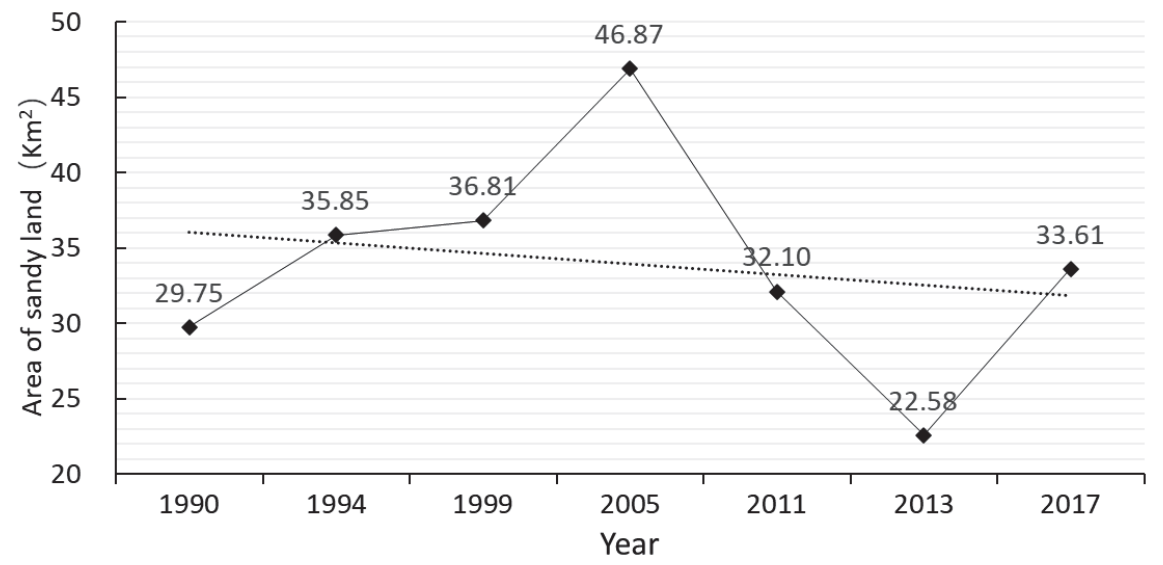

Fig. 6. The changing trend of sandy land area within the grassland in Zoige County from 1990 to 2017. 
a)

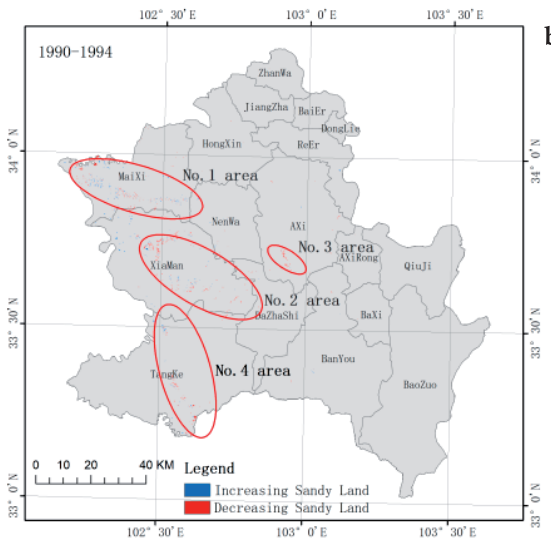

c)

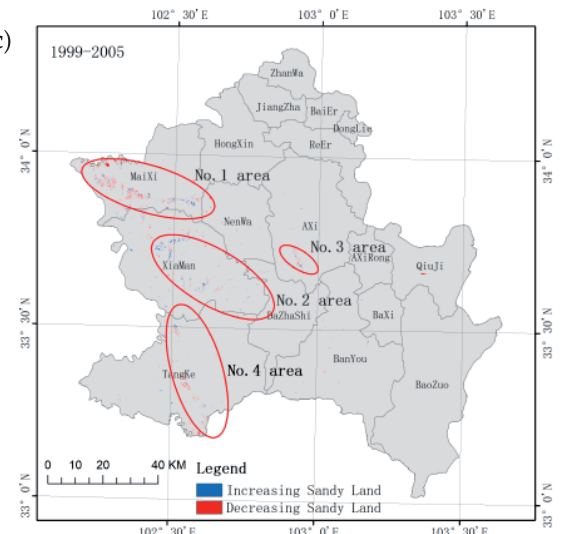

b)

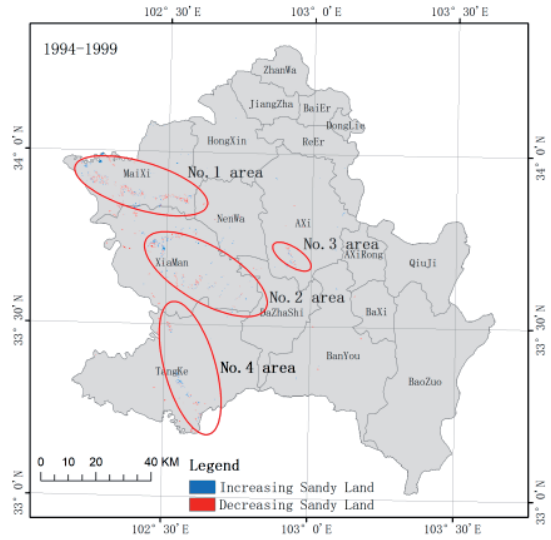

d)

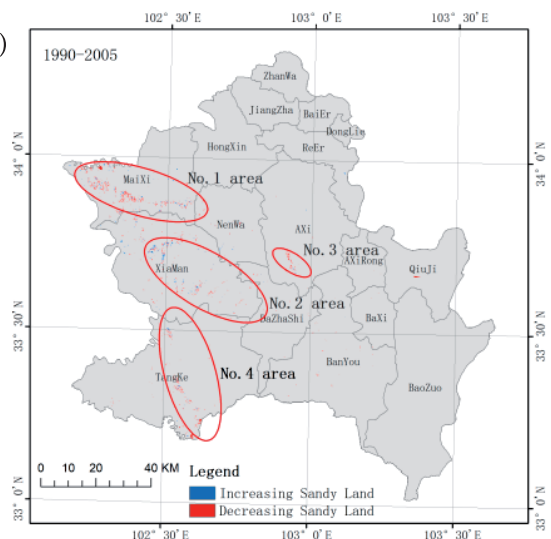

Fig. 7. The temporal and spatial evolution process of sandy land from 1990 to 2005 in Zoige County. a) Sandy land changes from 1990 to 1994; b) Sandy land changes from 1994 to 1999; c) Sandy land changes from 1999 to 2005; d) Sandy land changes from 1990 to 2005.
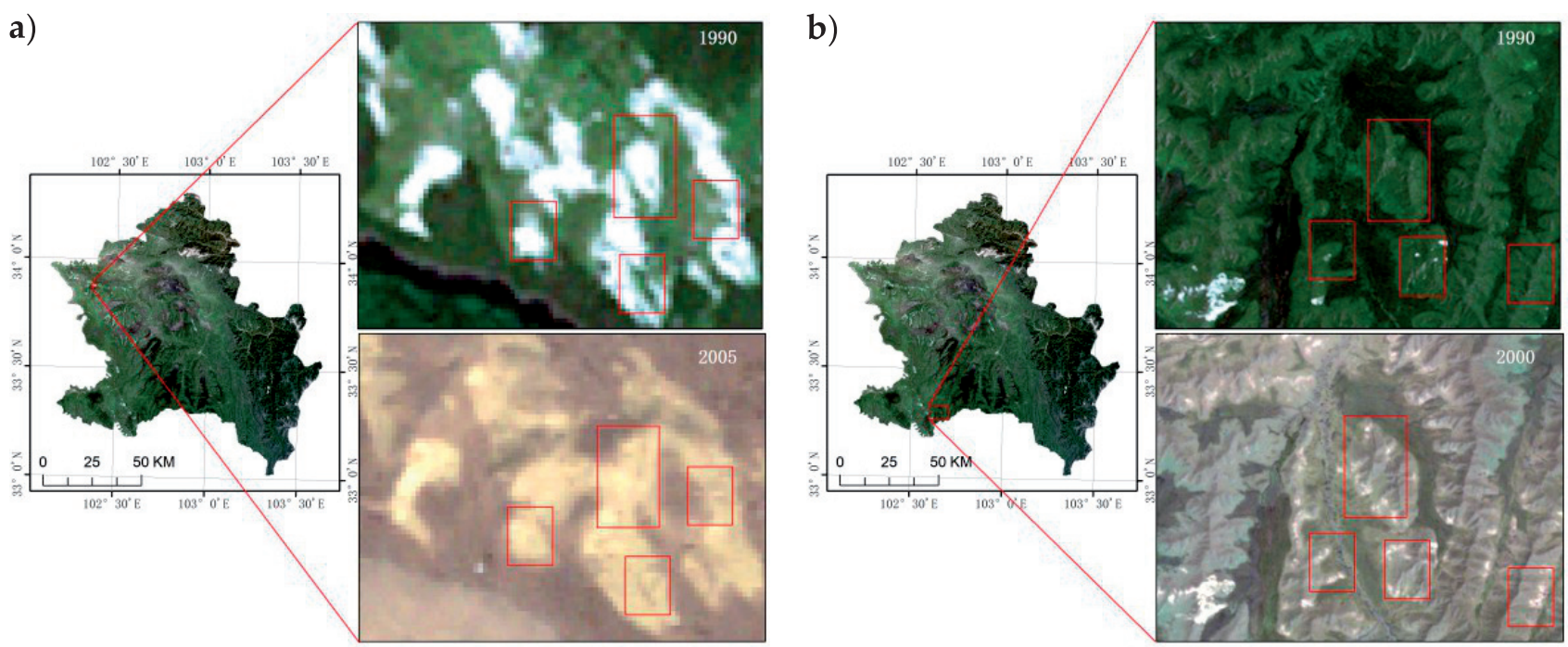

Fig. 8. a) The outward expansion at the edge of the original desertified land; b) The addition of spotty sandy patches.

especially topography, wind direction, and water resources distribution, are considered as the basic factors of grassland desertification. We overlaid the sandy land on the maps of a digital elevation model (DEM) and water resources distribution respectively, as shown in Fig. 11(a, b). Obviously, Zoige County can be divided into two parts by a mountain boundary (red line in Fig. 11a). Valleys occupy the northeast of Zoige County. Water resources are abundant, and forest is the main land cover in the area. However, there is not much water in the southwest of Zoige County and grassland is main vegetation type. The main wind direction in Zoige County is southwest, northwest, and northeast. The mountains to the southwest are eroded by the prevailing 

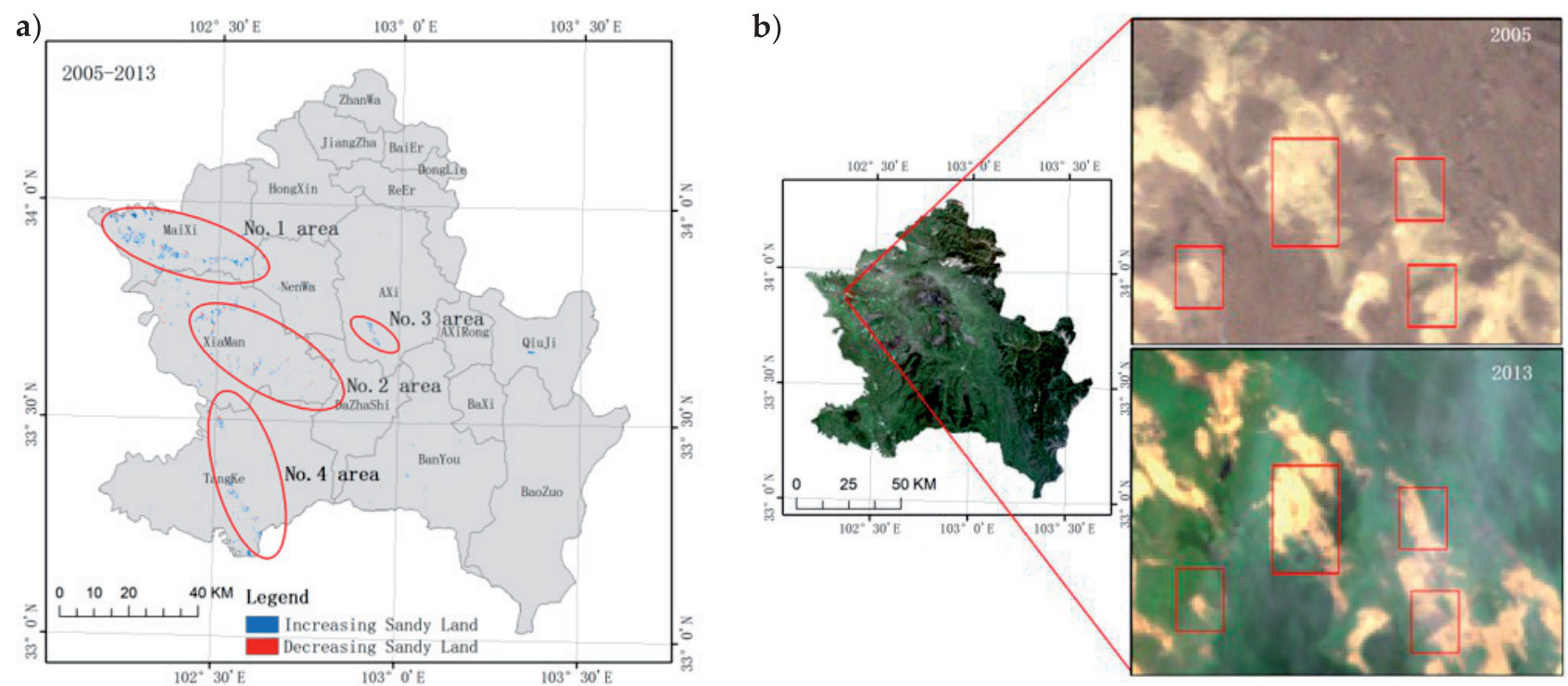

Fig. 9. a) The changes of grassland desertification area in Zoige County from 2005 to 2013; b) The local details of sandy land area reduction from 2005 to 2013.

wind all year around. Due to the combined influence of physiographic factors, sandy land is mainly distributed along the directions of the prevailing wind at the edges of mountains in the southwest. Thus, it can be assumed that physiographic characteristics of Zoige County determine the spatial distribution of sandy land.

In addition to natural factors, regional policy in desertification control plays an important role. According to the Chinese desertification control polices and their related documents, the desertification control in Zoige County started in the 1960s, but the control efforts were not strong. From 1991 to 2000, China

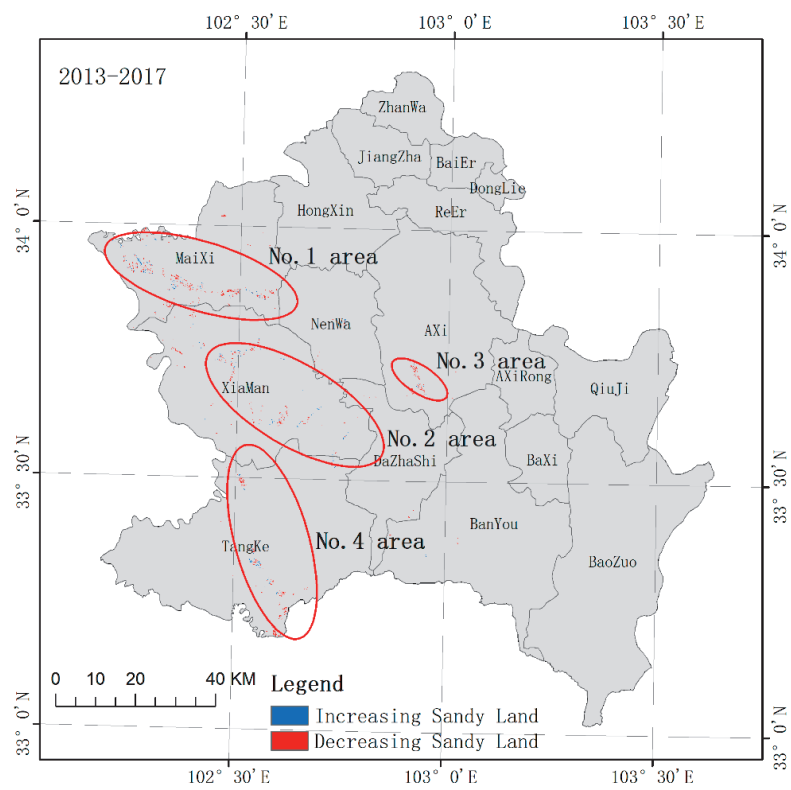

Fig. 10. The changes of grassland desertification area in Zoige County from 2013 to 2017. implemented the 'National Sand Control Project Plan'. However, it was not until 1993 that XiaMan township under the jurisdiction of Zoige County was listed as one of the demonstration bases of the national sand control project. During this period, although China emphasized the importance of desertification control in Zoige County, there was a lack in capital investment. From 1996 to 1999, a total of 2.8363 million yuan was invested in desertification control in Zoige County. Since 1999, a relatively mature desertification management model had been gradually promoted for application in Zoige County. Therefore, prior to 2005, desertification control measures existed in an exploratory stage for Zoige County was in the exploratory stage. Although some achievements were made, the desertification area continued to expand.

After 2005, more relevant policies were made at the country level to carry out large-scale desertification control work in Zoige County. From the perspective of capital investment, the national grassland desertification control projects in Zoige County were funded by central finance and supported financially at the provincial and local level, with a large scale of capital investment. During this period, desertification areas have been managed and protected regularly, resulting in a rapid decrease of sandy land. The UVA images at No. 1 and No. 3 monitoring points are shown in Fig. 12(a, b), respectively. Obviously, the vegetation of desertification land was gradually restored.

In recent years, however, the total area of grassland sandy land in Zoige County has presented an increasing trend. It was found from site investigation that some restored grassland returned once more to sandy land. In fact, the duration of protection for the restored grassland is usually three or five years and the surviving rate of artificial vegetation is very low, as shown in Fig. 12c). 
a) $102^{\circ} ; 0^{\circ}$ $102 * 30^{\prime} \mathrm{E}$ $103^{*} 0^{\prime} \mathrm{E}$ $103^{*} 30^{\circ} \mathrm{E}$

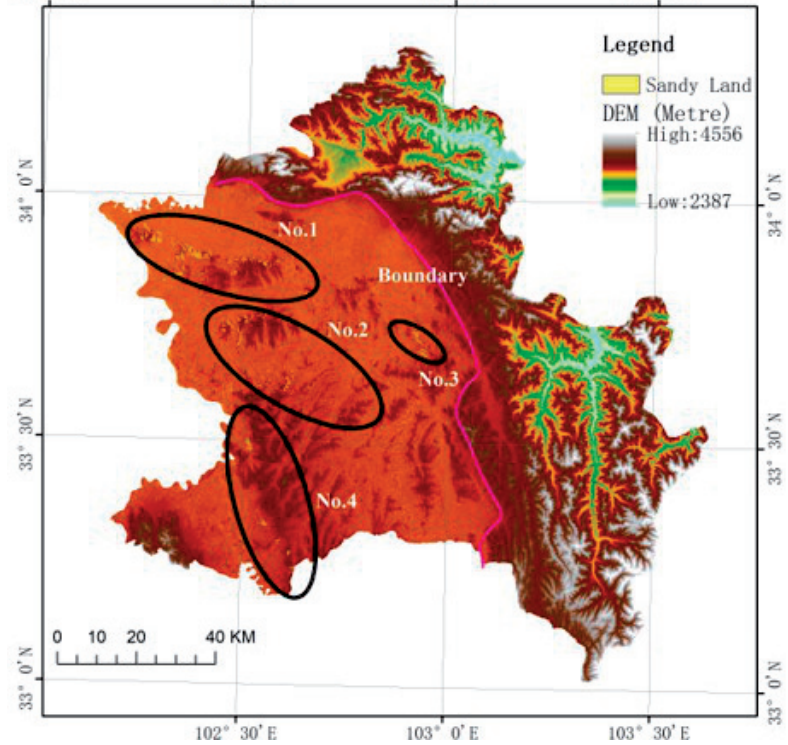

b)

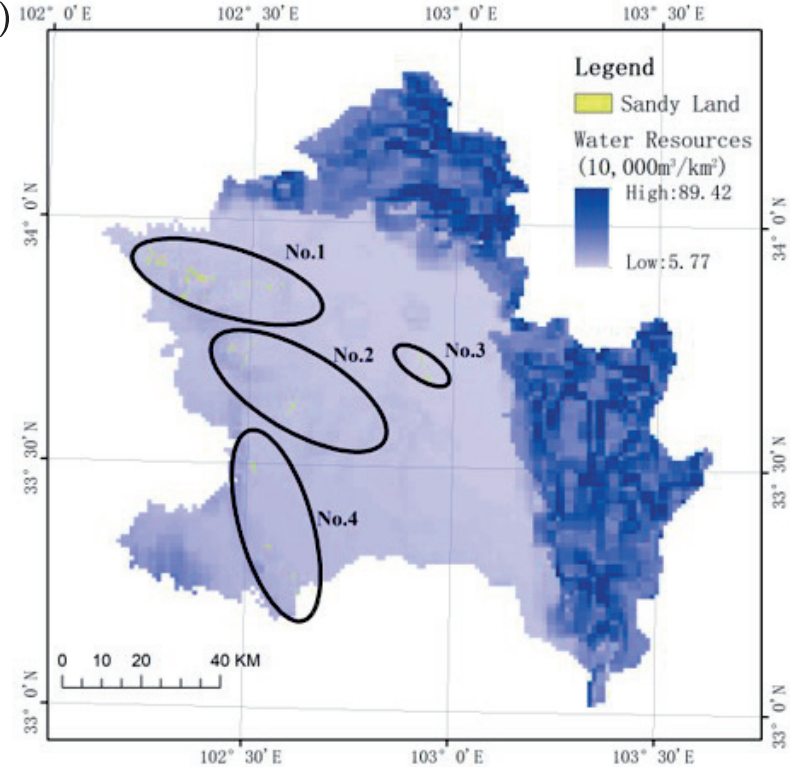

Fig. 11. a) The DEM and b) water resources distribution of Zoige County.

a)

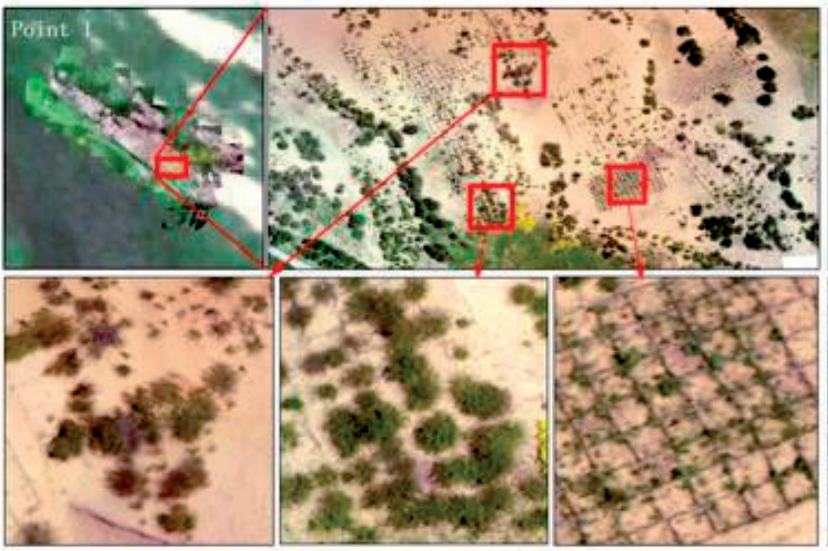

b)

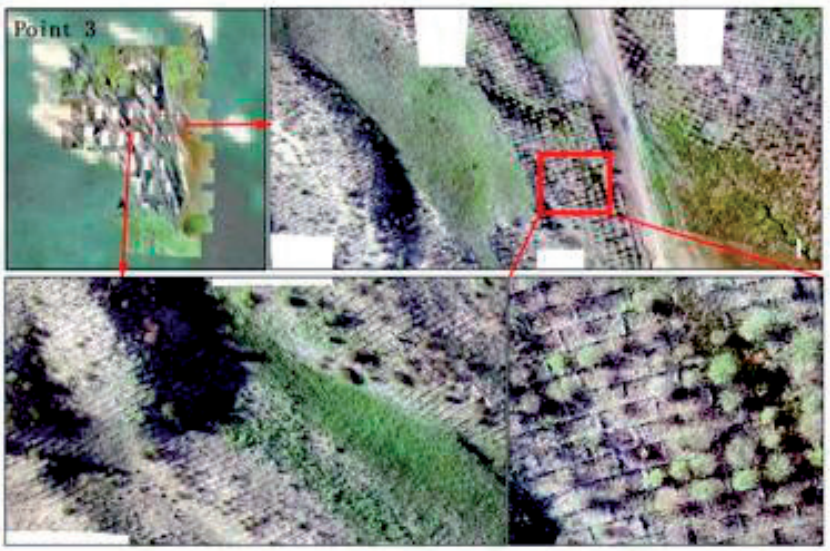

c)

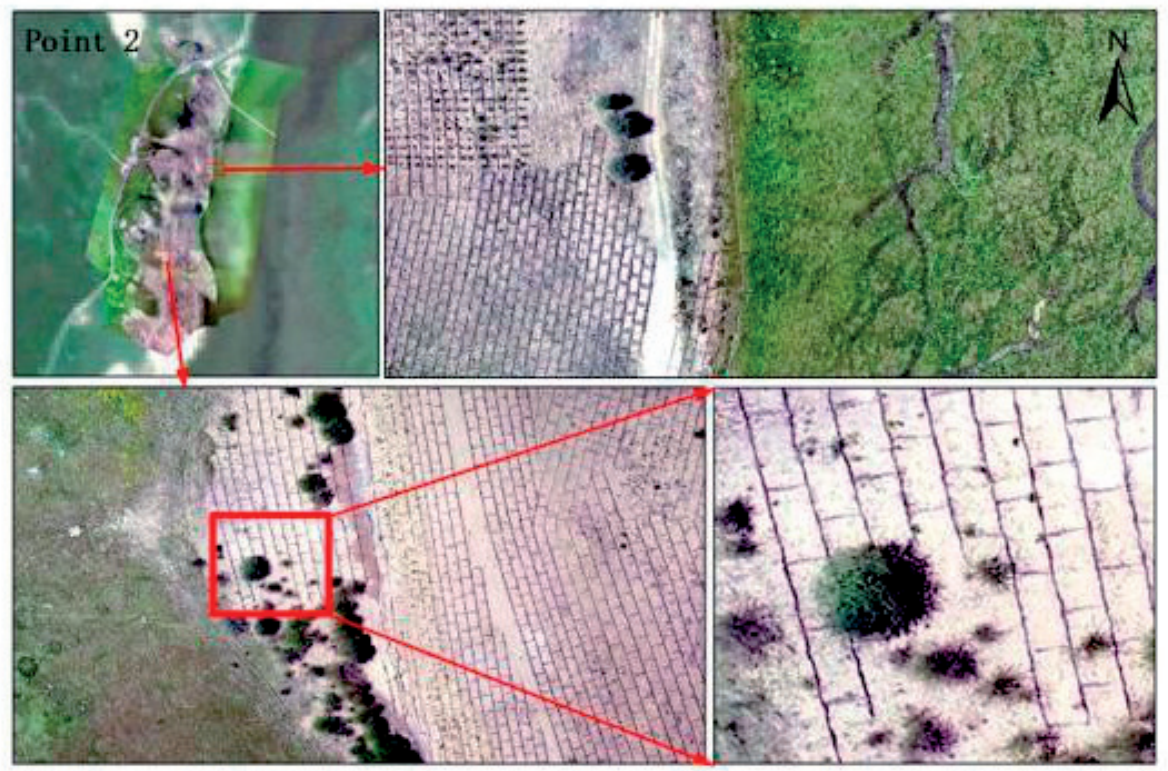

Fig. 12.a) UVA images at No. 1 monitoring point; b) UVA images at No. 3 monitoring point; c) UVA images at No.2 monitoring point. 


\section{Conclusions}

In Zoige County, desertification has been severe in the last three decades. This work focused on the analysis of space-time evolution of grassland desertification in Zoige County based on Landsat and UVA imagery. The results showed that the changing trend of the grassland sandy land area can be characterized by an " $N$ " type variation structure. The area of sandy lands increased from $29.75 \mathrm{~km}^{2}$ in 1990 to $46.87 \mathrm{~km}^{2}$ in 2005 and then decreased to $22.58 \mathrm{~km}^{2}$ in 2013. However, during 2014-2017, the area increased to $33.61 \mathrm{~km}^{2}$. The local natural environment conditions, especially topography, wind direction, and water resources distribution, are considered as the basic factors of causing grassland desertification. The combined influence of the physiographic factors determines the spatial distribution of sandy land. The sandy land in Zoige County is mainly distributed along the directions of the prevailing wind at the edges of mountains in the southwest. Regional policy and fund support play important roles in desertification control. It is clear that long-term protection works are necessary for the restored grassland. The results of the study are intended to support policy makers as they consider future directions for desertification control.

\section{Acknowledgements}

This research was funded by the Science and Technology Projects of Jiangxi Provincial Department of Education, grant number GJJ190934 and the Science and Technology Project of Aba state, grant number 19YYJSYJ0011.

\section{Conflict of Interest}

The authors declare no conflict of interest.

\section{References}

1. AZZOUZI S.A., VIDAL-PANTALEONI A., BENTOUNES H.A. Monitoring Desertification in Biskra, Algeria Using Landsat 8 and Sentinel-1A Images. IEEE Access, 6, 30844, 2018.

2. WEI H., WANG J., CHENG K., LI G., OCHIR A., DAVAASUREN D., CHONOKHUU S. Desertification information extraction based on feature space combinations on the Mongolian plateau. Remote Sensing, 10 (10), 1, 2018.

3. LI J., XU B., YANG X., QIN Z., ZHAO L., JIN Y., GUO J. Historical grassland desertification changes in the Horqin Sandy Land, Northern China (1985-2013). Scientific Reports, 7 (1), 1, 2017.

4. REYNOLDS J.F., MARK D., SMITH S., LAMBIN E.F., II B.L.T., MORTIMORE M., WALKER B. Global Desertification: Building a Science for Dryland Development. Science, 316, 2007.
5. D'ODORICO P., BHATTACHAN A., DAVIS K.F., RAVI S., RUNYAN C.W. Global desertification: Drivers and feedbacks. Advances in Water Resources, 51, 2013.

6. LYU Y., SHI P., HAN G., LIU L., GUO L., HU X., ZHANG G. Desertification control practices in China. Sustainability (Switzerland), 12 (8), 2020.

7. ZHAO H., ZHAO Y., GAO G., HO P. China's desertification deconstructed: towards a scientists' model based on long-term perceptions of grassland restoration (1995-2011). Restoration Ecology, 26 (April), S26, 2018.

8. SONG C., SCHROEDER T.A., COHEN W.B. Predicting temperate conifer forest successional stage distributions with multitemporal Landsat Thematic Mapper imagery. Remote Sensing of Environment, 106 (2), 2007.

9. WANG X., HUA T., LANG L., MA W. Spatial differences of aeolian desertification responses to climate in arid Asia. Global and Planetary Change, 148, 22, 2017.

10. WEI H., WANG J., HAN B. Desertification Information Extraction along the China-Mongolia Railway Supported by Multisource Feature Space and Geographical Zoning Modeling. IEEE Journal of Selected Topics in Applied Earth Observations and Remote Sensing, 13, 392, 2020.

11. ALBALAWI E.K., KUMAR L. Using remote sensing technology to detect, model and map desertification: A review. Journal of Food, Agriculture and Environment, 11 (2), 2013.

12. YANG G., CHEN D., HE X.L., LONG A.H., YANG M.J., LI X.L. Land use change characteristics affected by water saving practices in manas river basin, China using landsat satellite images. International Journal of Agricultural and Biological Engineering, 10 (6), 2017.

13. AHMADY-BIRGANI H., MCQUEEN K.G., MOEINADDINI M., NASERI H. Sand dune encroachment and desertification processes of the rigboland Sand Sea, Central Iran. Scientific Reports, 7 (1), 2017.

14. QI X., ZHANG C., WANG K. Comparing Remote Sensing Methods for Monitoring Karst Rocky Desertification at Sub-pixel Scales in a Highly Heterogeneous Karst Region. Scientific Reports, 9 (1), 1, 2019.

15. WEN Y., GUO B., ZANG W., GE D., LUO W., ZHAO H. Desertification detection model in Naiman Banner based on the albedo-modified soil adjusted vegetation index feature space using the Landsat8 OLI images. Geomatics, Natural Hazards and Risk, 11 (1), 544, 2020.

16. XU D., KANG X., QIU D., ZHUANG D., PAN J. Quantitative assessment of desertification using Landsat data on a regional scale - a case study in the Ordos Plateau, China. Sensors, 9 (3), 1738, 2009.

17. JIANG Z., HUETE A.R., CHEN J., CHEN Y., LI J., YAN G., ZHANG X. Analysis of NDVI and scaled difference vegetation index retrievals of vegetation fraction. Remote Sensing of Environment, 101 (3), 2006.

18. JULIEN Y., SOBRINO J.A., VERHOEF W. Changes in land surface temperatures and NDVI values over Europe between 1982 and 1999. Remote Sensing of Environment, 103 (1), 2006

19. GUO B., WEN Y. An Optimal Monitoring Model of Desertification in Naiman Banner Based on Feature Space Utilizing Landsat8 Oli Image. IEEE Access, 8, 4761, 2020.

20. YU H., LEE J.-Y., LEE W.-K., LAMCHIN M., TSERENDORJ D., CHOI S., KANG H.D. Feasibility of Vegetation Temperature Condition Index for monitoring desertification in Bulgan, Mongolia. Korean Journal of Remote Sensing, 29 (6), 621, 2013. 
21. LAMCHIN M., LEE J.Y., LEE W.K., LEE E.J., KIM M., LIM C.H., KIM S.R. Assessment of land cover change and desertification using remote sensing technology in a local region of Mongolia. Advances in Space Research, 57 (1), 2016.

22. WU Z., LEI S., BIAN Z., HUANG J., ZHANG Y. Study of the desertification index based on the albedo-MSAVI feature space for semi-arid steppe region. Environmental Earth Sciences, 78 (6), 2019.

23. LI F., MENG J., ZHU L., YOU N. Spatial pattern and temporal trend of land degradation in the Heihe River Basin of China using local net primary production scaling. Land Degradation and Development, 31 (4), 2020.

24. SUN J., HOU G., LIU M., FU G., ZHAN T.Y., ZHOU H., HAREGEWEYN N. Effects of climatic and grazing changes on desertification of alpine grasslands, Northern Tibet. Ecological Indicators, 107, 2019.

25. YANG X., YANG T., JI Q., HE Y., GHEBREZGABHER M.G. Regional-scale grassland classification using moderate-resolution imaging spectrometer datasets based on multistep unsupervised classification and indices suitability analysis. Journal of Applied Remote Sensing, 8 (1), 2014

26. JIANG M., TIAN S., ZHENG Z., ZHAN Q., HE Y. Human activity influences on vegetation cover changes in Beijing, China, from 2000 to 2015. Remote Sensing, 9 (3), 2017.

27. HIGGINBOTTOM T.P., SYMEONAKIS E. Assessing land degradation and desertification using vegetation index data: Current frameworks and future directions. Remote Sensing, 6 (10), 9552, 2014.

28. LIAN J., ZHAO X., LI X., ZHANG T., WANG S., LUO Y., FENG J. Detecting sustainability of desertification reversion: Vegetation trend analysis in part of the agropastoral transitional zone in Inner Mongolia, China. Sustainability (Switzerland), 9 (2), 2017.

29. FENG Q., MA H., JIANG X., WANG X., CAO S. What Has Caused Desertification in China? Scientific Reports, 5 (1), 1, 2015.

30. PIAO S., FANG J., LIU H., ZHU B. NDVI-indicated decline in desertification in China in the past two decades. Geophysical Research Letters, 32 (6), 1, 2005.
31. ZHANG Z., OUYANG Z., XIAO Y., XIAO Y., XU W. Using principal component analysis and annual seasonal trend analysis to assess karst rocky desertification in southwestern China. Environmental Monitoring and Assessment, 189 (6), 2017.

32. YANG J., WEISBERG P.J., BRISTOW N.A. Landsat remote sensing approaches for monitoring long-term tree cover dynamics in semi-arid woodlands: Comparison of vegetation indices and spectral mixture analysis. Remote Sensing of Environment, 119, 2012.

33. SOMERS B., ASNER G.P., TITS L., COPPIN P. Endmember variability in Spectral Mixture Analysis: A review. Remote Sensing of Environment, 2011.

34. FENG G., WANG K., YIN D., ZOU S., WANG L. How to account for endmember variability in spectral mixture analysis of night-time light imagery? International Journal of Remote Sensing, 41 (8), 2020.

35. SONG C. Spectral mixture analysis for subpixel vegetation fractions in the urban environment: How to incorporate endmember variability? Remote Sensing of Environment, 95 (2), 2005.

36. YUE Y., ZHANG B., WANG K., LIU B., LI R., JIAO Q., ZHANG M. Spectral indices for estimating ecological indicators of karst rocky desertification. International Journal of Remote Sensing, 31 (8), 2010.

37. GUO Q., FU B., SHI P., CUDAHY T., ZHANG J., XU $\mathrm{H}$. Satellite monitoring the spatial-temporal dynamics of desertification in response to climate change and human activities across the Ordos Plateau, China. Remote Sensing, 9 (6), 1, 2017.

38. XU E.Q., ZHANG H.Q., LI M.X. Object-Based Mapping of Karst Rocky Desertification using a Support Vector Machine. Land Degradation and Development, 26 (2), 2015.

39. LIU P., CHOO K.K.R., WANG L., HUANG F. SVM or deep learning? A comparative study on remote sensing image classification. Soft Computing, 21 (23), 7053, 2017. 
